\title{
Hydrogen Solubility in Heavy Undefined Petroleum Fractions Using Group Contributions Methods
}

\author{
Humberto Aguilar-Cisneros ${ }^{1}$, Verónica Uribe-Vargas ${ }^{2}$, Bernardo Carreón-Calderón ${ }^{2 *}$, \\ José Manuel Domínguez-Esquivel ${ }^{2}$ and Mario Ramirez-de-Santiago ${ }^{2}$ \\ 1 Universidad Nacional Autónoma de México (UNAM), Posgrado de Ingeniería, \\ Av. Universidad 3000, Ciudad Universitaria, Deleg. Coyoacan C.P. 04510 - México \\ ${ }^{2}$ Mexican Institute of Petroleum, Department of Reservoir Engineering, Eje Central Lázaro Cárdenas Norte \\ 152, Col. San Bartolo Atepehuacan, Deleg. Gustavo A. Madero, C.P. 07730 - México \\ e-mail: bcarreon@imp.mx \\ * Corresponding author
}

\begin{abstract}
Hydrogen solubility in heavy undefined petroleum fractions is estimated by taking as starting point a method of characterization based on functional groups [Carreón-Calderón et al. (2012) Ind. Eng. Chem. Res. 51, 14188-14198]. Such method provides properties entering into equations of states and molecular pseudostructures formed by non-integer numbers of functional groups. Using Vapor-Liquid Equilibria (VLE) data from binary mixtures of known compounds, interaction parameters between hydrogen and the calculated functional groups were estimated. Besides, the incorporation of the hydrogen-carbon ratio of the undefined petroleum fractions into the method allows the corresponding hydrogen solubility to be properly estimated. This procedure was tested with seven undefined petroleum fractions from 27 to 6 API over wide ranges of pressure and temperature (323.15 to $623.15 \mathrm{~K})$. The results seem to be in good agreement with experimental data (overall Relative Average Deviation, RAD $<15 \%$ ).
\end{abstract}

Résumé - Solubilité de l'hydrogène dans des fractions indéfinies du pétrole lourd à l'aide de la méthode de contribution de groupes - La solubilité de l'hydrogène dans des fractions indéfinies du pétrole lourd est estimée en prenant comme point de départ la méthode de contribution de groupes [Carreón-Calderón et al. (2012) Ind. Eng. Chem. Res. 51, 14188-14198]. Cette méthode fournit les paramètres d'entrée de l'équation d'état et une pseudo-structure moléculaire formée par des nombres non entiers pour les groupes fonctionnels. En utilisant les données de l'équilibre liquide-vapeur des mélanges binaires de composants connus, les paramètres d'interaction entre l'hydrogène et les groupes fonctionnels sont déterminés. En plus, l'incorporation du rapport hydrogène-carbone des fractions indéfinies du pétrole dans la méthode décrite permet d'estimer correctement la solubilité de l'hydrogène. Cette méthode a été testée avec sept fractions indéfinies de densité API de 6 à 27, et sur une large plage de pressions et de températures $(323.15$ à $623.15 \mathrm{~K})$. Les résultats montrent un bon accord avec les données expérimentales (erreur moyenne relative globale $<15 \%$ ). 


\section{NOTATION}

$A \quad$ Parameter of the equation of state

$A_{1}-A_{3} \quad$ Coefficients in Equation (5)

$a_{1}-a_{4} \quad$ Coefficients in Equations (11)-(14)

$B \quad$ Parameter of the equation of state

$b_{1}-b_{4} \quad$ Coefficients in Equations (11)-(14)

$\mathrm{C}_{k} \quad$ Carbon number of defined hydrocarbons

$c_{1} \quad$ Coefficient in Equation (11)

$d_{1} \quad$ Coefficient in Equation (11)

$F G \quad$ Number of functional groups types

$F_{\text {Obj }} \quad$ Objective Function

$\mathrm{H} / \mathrm{C} \quad$ Hydrogen carbon ratio

$M W \quad$ Molecular Weight

$N \quad$ Number of data points

$P \quad$ Pressure

$P_{\mathrm{c}} \quad$ Critical Pressure

$p_{\mathrm{c}} \quad$ Contribution to $P_{\mathrm{c}}$ by functional groups

$P_{\text {Sat }} \quad$ Saturation Pressure

$R \quad$ Universal constant of gases, $8.31441 \mathrm{~J} / \mathrm{mol} \mathrm{K}$

$\begin{array}{ll}\mathrm{RAD} \% & \text { Relative Average Deviation }=\frac{100}{N} \sum_{i=1}^{N}\left(\frac{\left|x_{i}^{\mathrm{Exp}}-x_{i}^{\mathrm{Ca}}\right|}{x_{i}^{\mathrm{Exp}}}\right) \\ T & \text { Temperature }\end{array}$

$T_{\mathrm{c}} \quad$ Critical temperature

$V \quad$ Molar volume, $\mathrm{m}^{3} / \mathrm{mol}$

$V_{\mathrm{c}} \quad$ Critical volume, $\mathrm{m}^{3} / \mathrm{mol}$

$v_{\mathrm{Ci}} \quad$ Contribution to $V_{c}$ by functional groups

$x \quad$ Mole fraction

Z Compressibility factor

\section{GREEK LETTERS}

$\alpha \quad$ Coefficient in Equation (9)

$\beta \quad$ Coefficient in Equation (9)

$\chi \quad$ Coefficient in Equation (9)

$\Delta v \quad$ Group volume increment in Equations (4) and (5)

$\Phi \quad$ Fugacity coefficient

$\rho \quad$ Mass density, $\mathrm{kg} / \mathrm{m}^{3}$

$v \quad$ Number of functional groups

$\omega \quad$ Acentric factor

\section{SUPERSCRIPTS}

Cal Calculated data

L Liquid phase

Exp Experimental data

\section{SUBSCRIPTS}

c Critical property

$k \quad$ Carbon number $k$ $i \quad$ Functional group $i$ or pure component $i$

$j \quad$ Undefined petroleum fractions $j$ or pure component $j$

\section{INTRODUCTION}

Hydrogen solubility predictions are essential part in several processes in the petroleum and chemical industries; for instance, hydrocracking and hydrogenation processes are used to transform heavy oil into more valuable products. Hydrogen solubility data are required for designing and operating such processes and it is also needed in the corresponding kinetic models (Saajanlehto et al., 2014). Several authors have pointed out the importance of taking into account Vapor-Liquid Equilibria (VLE) in reaction modeling and its influence in conversion predictions (Chen et al., 2011; Hook, 1985; Pellegrini et al., 2008). A detailed review about VLE of hydrogen and petroleum fraction systems was presented by Chávez et al. (2014). They presented experimental data and modeling methods, most of which were conducted for systems composed of hydrogen and defined hydrocarbons, with few systems formed by hydrogen and undefined petroleum fractions. This may be attributable to the lack of experimental data, making a hard task to develop accurate prediction methods. Besides, binary systems containing hydrogen all exhibit a type III phase behavior in the classification scheme of Van Konynenburg and Scott (Privat and Jaubert, 2013) which cannot be predicted with cubic Equations Of State (EOS) using classical mixing rules because of the quantum nature of hydrogen and the mixture size-asymmetry (Deiters, 2013). Despite these issues, most methods found in literature use cubic Equations Of State (EOS) because of their mathematical simplicity and their capability of modeling multicomponent mixtures over a wide range of temperatures and pressures. To overcome such limitations several authors have proposed to fit EOS parameters to VLE data (Qian et al., 2013); however, in general, their capability of prediction is reduced with such regressions. New approaches have been suggested in order to preserve the predictive features of cubic equations of state, such as that described by Jaubert et al. (2010). In such approach, binary interaction parameters are predicted by using a group contribution method, where classical cubic equations of state and excess free energy models $\left(\mathrm{EOS} / \mathrm{g}^{\mathrm{E}}\right)$ are combined, being applied successfully to binary mixtures of hydrogen with defined hydrocarbons (Qian et al., 2013).

A further challenge is the mathematical characterization of the undefined petroleum fraction; that is, the determination of its physical-chemical properties by mathematical means. In such characterization process, it is important to 
find a convenient number of pseudocomponents in which the undefined petroleum fraction will be divided. According to Lin et al. (1985), better results are obtained as the number of pseudocomponents increases when VLE of systems formed by hydrogen and undefined fractions are modeled. On the other hand, Chávez concluded that 30 pseudocomponents are enough to obtain good agreement between calculated and experimental data. The characterization procedure also involves estimation of the corresponding critical properties entering into cubic equations of state. These properties are frequently calculated from correlations (Firoozabadi, 1988; Lee and Kesler, 1975; Pedersen et al., 2004), but they do not always lead to the same results, because each one was developed for different sets of fluids at limited conditions. Thus, recently, group contribution methods have been recently extended to pseudocomponents, showing a good performance (Carreón-Calderón et al., 2012; Xu et al., 2015).

Carreón-Calderón et al. (2012) presented a new characterization procedure based on group contribution methods. They used selected functional groups to assign a hypothetical chemical structure to an undefined petroleum fraction by a minimization process of its corresponding Gibbs free energy. This methodology was applied to simulate VLE of heavy (Carreón-Calderón et al., 2014) and light hydrocarbons (Uribe-Vargas et al., 2016). Good results were achieved in both cases without making use of correlations to calculate critical properties or adjusted binary interaction parameters. In particular, they modeled vapor-liquid equilibria of heavy petroleum fluids, where no significant differences were shown regardless of the number of pseudocomponents used in modeling. These results show the feasibility of applying this characterization procedure to VLE of hydrogen with heavy undefined petroleum fraction. In this work, we add hydrogen functional group to the set of functional groups original proposed and suggest modifications to the characterization procedure in order to determine the hydrogen solubility properly. The entire methodology was tested with experimental data found in literature: Venezuelan Heavy Coking Gas Oil (HGCO) (Ji et al., 2013), Karamay Atmospheric Residue (KRAR) (Ji et al., 2013), Liaohe Atmospheric Residue (LHAR) (Ji et al., 2013), Venezuelan Atmospheric Residue (VNAR) (Ji et al., 2013), Canadian Light Virgin Gas Oil (CLVGO) (Cai et al., 2001), Canadian Heavy Virgin Gas Oil (CHVGO) (Cai et al., 2001) and Athabasca Bitumen (AB) (Lal et al., 1999).

\section{CHARACTERIZATION PROCEDURE}

The approach presented by Carreón-Calderón et al. (2012) is used to determine the properties of the undefined petroleum fractions. In that methodology, a hypothetical structure is calculated with a set of selected functional groups, which depend on the group contribution method used. CarreónCalderón et al. $(2012,2014)$ have suggested two group contribution methods; Joback-Reid (JR) (Joback and Reid, 1987) and Marrero-Gani (MG) (Marrero and Gani, 2001). JR method was suggested to simulate VLE of light petroleum fluids (Uribe-Vargas et al., 2016), while MG method showed better functionality in heavy petroleum fluids heavier than 14 API (Carreón-Calderón et al., 2014). In the latter, the $\mathrm{C}_{7+}$ fraction, which has unknown composition, was split in 3, 6 and 9 pseudocomponents, founding no significant difference between calculations and experiments regardless of the fraction splitting. Accordingly, in this work, the undefined petroleum fractions are treated as a single pseudocomponent in order to have a simpler characterization, where their corresponding properties are calculated through MG method.

Table 1 shows the functional groups of the MG method and the equivalent groups of the GCVOL (Elbro et al., 1991; Ihmels and Gmehling, 2003) method for determining liquid densities, as originally proposed by Carreón-Calderón et al. (2012). A quick review of these functional groups was made and it was found that the last functional groups are not equivalent each other $(a C \neq A C-C)$. Therefore, in this work the last functional group $(a C)$ was changed to $a C-C$ functional group from the same MG method.

An optimization process is used to estimate a hypothetical chemical structure of the undefined petroleum fraction, where its Gibbs free energy is the objective function to be minimized. Since the undefined fraction is treated like a pure component, minimize the liquid fugacity coefficient $\left(\phi_{i}^{L}\right)$ is equivalent to minimize the Gibbs energy. Thus, the objective function is:

$$
\begin{gathered}
\min _{v_{1}, v_{2}, \cdots, v_{F G} \geq 0} \phi_{i}^{L}\left[T_{\mathrm{Ci}}\left(v_{1}, v_{2}, \cdots, v_{F G}\right), P_{\mathrm{C} i}\left(v_{1}, v_{2}, \cdots, v_{F G}\right),\right. \\
\left.\omega_{i}\left(v_{1}, v_{2}, \cdots, v_{F G}\right)\right]
\end{gathered}
$$

where $T_{\mathrm{C}}, P_{\mathrm{C}}$ and $\omega$ are the critical temperature, critical pressure and acentric factor, respectively, with $F G$ being the number of functional groups types. The $\phi_{i}^{L}$ expression depends on the cubic EOS selected; in this work, the Peng-Robinson cubic Equation Of State PR-EOS (Peng and Robinson, 1976) is used to determine the fugacity coefficient as follows:

$$
\begin{aligned}
\ln \left(\phi_{i}^{L}\right)= & \left(Z^{L}-1\right) \ln \left(Z^{L}-B\right) \\
& -\frac{A}{2 \sqrt{2} B} \ln \left(\frac{Z^{L}+(\sqrt{2}+1) B}{Z^{L}-(\sqrt{2}-1) B}\right)
\end{aligned}
$$

where $Z^{L}=P V^{L} /(R T)$ is the compressibility factor of the liquid phase, $A$ and $B$ are PR-EOS parameters. The properties of 
TABLE 1

Original functional groups.

\begin{tabular}{c|c}
\hline Marrero-Gani & GCVOL \\
\hline$-\mathrm{CH}_{3}$ & $-\mathrm{CH}_{3}$ \\
\hline$-\mathrm{CH}_{2}$ - (chain) & $-\mathrm{CH}_{2}$ - (chain) \\
\hline$>\mathrm{CH}$ - (chain) & $>\mathrm{CH}$ - (chain) \\
\hline $\mathrm{C}$ (chain) & $\mathrm{C}$ (chain) \\
\hline $\mathrm{CH}_{2}$ (cyclic) & $\mathrm{CH}_{2}$ (cyclic) \\
\hline $\mathrm{CH}$ (cyclic) & $\mathrm{CH}$ (cyclic) \\
\hline $\mathrm{C}$ (cyclic) & $\mathrm{C} \mathrm{(cyclic)}$ \\
\hline aCH & $\mathrm{ACH}$ \\
\hline $\mathrm{aC}$ fused with aromatic ring & $\mathrm{AC}-\mathrm{C}$ \\
\hline
\end{tabular}

undefined petroleum fractions are usually given at standard conditions; hence, the pressure $P$ and temperature $T$ are set equal to $0.101325 \mathrm{MPa}$ and $288.15 \mathrm{~K}$, respectively; $v^{L}$ is the molar liquid volume and $R$ is the gas constant.

This minimization problem is constrained by the molecular weight and density of the corresponding undefined petroleum fraction:

$$
\begin{gathered}
\sum_{j=1}^{F G} v_{j} M W_{j}-M W_{i}=0 \\
\sum_{j=1}^{F G} v_{j} \Delta v_{j}-\frac{M W_{i}}{\rho_{i}^{L}}=0
\end{gathered}
$$

In the above expression, subscripts $j$ and $i$ indicate the functional group $j$ of the undefined fraction $i, M W$ is the molecular weight, $v_{j}$, the number (coefficient) of a functional group, $\Delta v_{j}$ the volume increment, $\rho_{i}^{L}$ the liquid density. The $\Delta v_{j}$ is expressed as a function of temperature by means of

$$
\Delta v_{j}=A_{1}+A_{2} T+A_{3} T^{2}
$$

where $A_{1}, A_{2}$ and $A_{3}$ are the parameters of the GCVOL approach (Ihmels and Gmehling, 2003).

Finally, to solve the minimization problem, Equation (2) requires critical properties $\left(T_{\mathrm{C}}, P_{\mathrm{C}}\right.$ and $\left.\omega\right)$. These properties are calculated using Equations from (6) to (8), where, the temperature is in $\mathrm{K}$, pressures in $\mathrm{MPa}$ and volume in $\mathrm{m}^{3} / \mathrm{mol}$ (Marrero and Gani, 2001).

$$
T_{\mathrm{C}}=231.239 \ln \left(\sum_{i=1}^{F G} v_{i} t_{\mathrm{C} i}\right)
$$

$$
\begin{gathered}
P_{\mathrm{C}}=0.1\left(\sum_{i=1}^{F G} v_{i} p_{\mathrm{C} i}+0.108998\right)^{-2}+0.59827 \\
V_{\mathrm{C}}=\left(7.95+\sum_{i=1}^{F G} v_{i} v_{\mathrm{C} i}\right) \times 10^{-6}
\end{gathered}
$$

In previous equations $t_{\mathrm{C} i}, p_{\mathrm{C} i}$ and $v_{\mathrm{C} i}$ represent contributions to the critical temperature, the critical pressure, and the critical molar volume because of the presence of a defined functional group $i$ in a molecule.

One of the major contributions of the characterization procedure described above is the assignment of a hypothetical chemical structure to an undefined petroleum fraction. This allows us to handle the undefined fraction as hypothetical pure component and, in principle, to make use of any thermodynamic model exclusively developed for known components and their mixtures. Thus, in addition to PR-EOS, Huron-Vidal (Michelsen, 1990) mixing rule together with the UNIversal quasi-chemical Functional group Activity Coefficients (UNIFAC) approach, as activity coefficient model, are used also in this work for calculating VLE of hydrogen and heavy petroleum fluids, where the group-interaction parameters $\Psi_{n m}$ in the UNIFAC approach are given by

$$
\Psi_{n m}=\exp -\frac{\alpha_{n m}+\beta_{n m} T+\chi_{n m} T^{2}}{T}
$$

The parameters $\alpha_{n m}, \beta_{n m}$ and $\chi_{n m}$ are specific parameters for a couple of functional groups $n$ and $m$, whose values are obtained from literature (Horstmann et al., 2005). Notice that $\alpha_{n m} \neq \alpha_{m n}, \beta_{n m} \neq \beta_{m n}, \chi_{n m} \neq \chi_{m n}$. It is worth pointing out that hydrogen is handled as a single functional group.

\section{SOLUBILITY OF HYDROGEN IN DEFINED HYDROCARBON COMPONENTS}

Before proceeding with the calculation of VLE of systems composed of hydrogen and heavy petroleum fluids, the hydrogen solubility in defined hydrocarbons was estimated in order to evaluate the thermodynamic models and their corresponding binary parameters described above.

Table 2 shows the 13 binary systems involved in this study, which are formed by nine paraffinic and four aromatic compounds. The range of experimental temperatures and pressures are also included and the comparison of calculated with experimental values are given in Table 3.

As observed, hydrogen solubility estimation is smaller than the experimental values in all cases. The difference is 
TABLE 2

List of 13 binary mixtures used in this study.

\begin{tabular}{|c|c|c|c|c|c|c|c|}
\hline System & Short name & \multicolumn{2}{|c|}{$T_{\text {range }}(\mathrm{K})$} & \multicolumn{2}{|c|}{$P_{\text {range }}(\mathrm{Mpa})$} & \multirow{2}{*}{$\begin{array}{c}\text { Data points } \\
81\end{array}$} & \multirow{2}{*}{$\begin{array}{c}\text { Data source } \\
\text { (Connolly and } \\
\text { Kandalic, 1986) }\end{array}$} \\
\hline Pentane-hydrogen & $\mathrm{C}_{5} \mathrm{H}_{12}-\mathrm{H}_{2}$ & 308.15 & 463.15 & 2.862 & 14.087 & & \\
\hline Hexane-hydrogen & $\mathrm{C}_{6} \mathrm{H}_{14}-\mathrm{H}_{2}$ & 301.93 & 446.26 & 3.45 & 68.95 & 67 & $\begin{array}{c}\text { (Nichols et al. } \\
\text { 1957) }\end{array}$ \\
\hline Heptane-hydrogen & $\mathrm{C}_{7} \mathrm{H}_{16}-\mathrm{H}_{2}$ & 424.15 & 498.85 & 2.45 & 78.45 & 23 & \multirow[t]{2}{*}{ (Young, 1981) } \\
\hline Octane-hydrogen & $\mathrm{C}_{8} \mathrm{H}_{18}-\mathrm{H}_{2}$ & 298.15 & 543.15 & 0.69 & 19.00 & 75 & \\
\hline Decane-hydrogen & $\mathrm{C}_{10} \mathrm{H}_{22}-\mathrm{H}_{2}$ & 283.17 & 447.92 & 1.24 & 14.22 & 103 & \multirow{5}{*}{$\begin{array}{l}\text { (Florusse et al., } \\
\text { 2003) }\end{array}$} \\
\hline Hexadecane-hydrogen & $\mathrm{C}_{16} \mathrm{H}_{34}-\mathrm{H}_{2}$ & 298.13 & 448.17 & 1.15 & 15.13 & 113 & \\
\hline Octacosane-hydrogen & $\mathrm{C}_{28} \mathrm{H}_{58}-\mathrm{H}_{2}$ & 342.56 & 447.34 & 1.46 & 14.00 & 56 & \\
\hline Hexatriacontane-hydrogen & $\mathrm{C}_{36} \mathrm{H}_{74}-\mathrm{H}_{2}$ & 357.53 & 447.43 & 1.38 & 14.34 & 41 & \\
\hline Hexatetracontane-hydrogen & $\mathrm{C}_{46} \mathrm{H}_{96}-\mathrm{H}_{2}$ & 372.52 & 447.51 & 2.29 & 15.97 & 36 & \\
\hline Benzene-hydrogen & $\mathrm{C}_{6} \mathrm{H}_{6}-\mathrm{H}_{2}$ & 323.2 & 423.1 & 2.55 & 15.73 & 18 & \multirow{4}{*}{ (Park et al., 1996) } \\
\hline Napthalene-hydrogen & $\mathrm{C}_{10} \mathrm{H}_{8}-\mathrm{H}_{2}$ & 373.2 & 423.2 & 4.29 & 19.39 & 14 & \\
\hline Phenanthrene-hydrogen & $\mathrm{C}_{14} \mathrm{H}_{10}-\mathrm{H}_{2}$ & 383.2 & 423.2 & 5.89 & 21.69 & 12 & \\
\hline Pyrene-hydrogen & $\mathrm{C}_{16} \mathrm{H}_{10}-\mathrm{H}_{2}$ & 433.2 & 433.2 & 5.17 & 19.73 & 6 & \\
\hline
\end{tabular}

higher as the carbon number of the component increases; the Relative Average Deviation (RAD) increases from 13\% for pentane to $75 \%$ for hexatetracontane, whereas, in the case of aromatic compounds increases from $32 \%$ to $52 \%$ for benzene and pyrene, respectively. Because of these results, group-interaction parameters $\Psi_{n m}$ were calculated again by fitting calculations to the available VLE experimental data in Table 2. This fitting process requires to identify the functional groups forming the defined components. In case of paraffinic compounds, they can be represented by $-\mathrm{CH}_{3}$ and $-\mathrm{CH}_{2}$ functional groups, and aromatic compounds by $\mathrm{ACH}$ and $\mathrm{AC}$ functional groups. Because $-\mathrm{CH}_{3}$ and $\mathrm{AC}$ belongs to the main group $1\left(-\mathrm{CH}_{2}\right)$ and $3(\mathrm{ACH})$ respectively, only interaction parameters between $-\mathrm{CH}_{2}$ and $\mathrm{H}_{2}$, $\mathrm{ACH}$ and $\mathrm{H}_{2}$, and $\mathrm{ACH}$ and $\mathrm{CH}_{2}$ are required.

Table 4 shows the original $\alpha_{n m}$ parameters between main functional groups.

In the fitting process, for simplicity, parameter $\alpha_{n m}$ is adjusted while $\beta_{n m}$ and $\chi_{n m}$ parameters keep their original values. The fitted group-interaction parameters are obtained by a minimization process, where the objective function $\left(F_{\mathrm{Obj}}\right)$ is given by

$$
F_{\mathrm{Obj}}=\frac{\sqrt{\sum_{i=1}^{N}\left[P_{\mathrm{Sat}_{i}^{\mathrm{Exp}}}-P_{\mathrm{Sat}_{i}^{\mathrm{Cal}}}\left(\alpha_{n m}, \alpha_{m n}\right)\right]^{2}}}{N}
$$

TABLE 3

RAD of hydrogen solubility in defined hydrocarbons.

\begin{tabular}{c|c|c}
\hline System & $\begin{array}{c}\text { Original UNIFAC } \\
\text { parameters RAD (\%) }\end{array}$ & This work RAD (\%) \\
\hline $\mathrm{C}_{5} \mathrm{H}_{12}-\mathrm{H}_{2}$ & 12.07 & 11.81 \\
\hline $\mathrm{C}_{6} \mathrm{H}_{14}-\mathrm{H}_{2}$ & 23.27 & 10.39 \\
\hline $\mathrm{C}_{7} \mathrm{H}_{16}-\mathrm{H}_{2}$ & 13.13 & 6.91 \\
\hline $\mathrm{C}_{8} \mathrm{H}_{18}-\mathrm{H}_{2}$ & 42.80 & 24.57 \\
\hline $\mathrm{C}_{10} \mathrm{H}_{22}-\mathrm{H}_{2}$ & 37.81 & 3.65 \\
\hline $\mathrm{C}_{16} \mathrm{H}_{34}-\mathrm{H}_{2}$ & 53.11 & 1.19 \\
\hline $\mathrm{C}_{28} \mathrm{H}_{58}-\mathrm{H}_{2}$ & 69.61 & 6.06 \\
\hline $\mathrm{C}_{36} \mathrm{H}_{74}-\mathrm{H}_{2}$ & 74.82 & 3.98 \\
\hline $\mathrm{C}_{46} \mathrm{H}_{96}-\mathrm{H}_{2}$ & 82.87 & 6.83 \\
\hline $\mathrm{C}_{6} \mathrm{H}_{6}-\mathrm{H}_{2}$ & 32.49 & 1.89 \\
\hline $\mathrm{C}_{10} \mathrm{H}_{8}-\mathrm{H}_{2}$ & 42.62 & 3.72 \\
\hline $\mathrm{C}_{14} \mathrm{H}_{10}-\mathrm{H}_{2}$ & 47.40 & 11.00 \\
\hline $\mathrm{C}_{16} \mathrm{H}_{10}-\mathrm{H}_{2}$ & 51.89 & \\
\hline & & 3.37 \\
\hline
\end{tabular}

Here $P_{\mathrm{Sat}_{i}^{\mathrm{Exp}}}$ and $P_{\mathrm{Sat}_{i}^{\mathrm{Cal}}}$ are the experimental and calculated saturation pressure on the bubble point respectively and $N$ represent the number of data points. The result of this 
TABLE 4

Original group-interaction parameters $\left(\alpha_{n m}, \alpha_{m n}\right)$ between functional groups used in this study (Horstmann et al., 2005).

\begin{tabular}{c|c|c|c|c|c|c}
\hline & & \multicolumn{2}{|c|}{ Main group 1 - $\mathrm{CH}_{2}$} & \multicolumn{2}{c}{ Main group 2 ACH } & Main group 62 $\mathrm{H}_{2}$ \\
\hline \multirow{2}{*}{$\begin{array}{c}\text { Main group 1 } \\
-\mathrm{CH}_{2}\end{array}$} & $-\mathrm{CH}_{2}$ & $-\mathrm{CH}_{2}$ & $-\mathrm{CH}_{3}$ & ACH & AC \\
\cline { 2 - 7 } & $-\mathrm{CH}_{3}$ & & 61.13 & 61.13 & 613.30 \\
\hline $\begin{array}{c}\text { Main group 2 } \\
\text { ACH }\end{array}$ & $\mathrm{ACH}$ & -11.12 & -11.12 & & 613.13 \\
\cline { 2 - 7 }
\end{tabular}

fitting process is a group of new parameters $\left(\alpha_{n m}, \alpha_{m n}\right)$ for each binary mixtures $\left(\mathrm{H}_{2}\right.$-hydrocarbon). Figures $1 \mathrm{a}$ and $1 \mathrm{~b}$ show the trend of $\alpha_{n m}$ and $\alpha_{m n}$ parameters for paraffinic and aromatic compounds as function of the carbon number. The correlated parameters take the form of:

$$
\begin{gathered}
\alpha_{\mathrm{H}_{2}-\mathrm{CH}_{2}}=a_{1} \ln \left(b_{1} \mathrm{C}_{k}+c_{1}\right)+d_{1} \\
\alpha_{\mathrm{CH}_{2}-\mathrm{H}_{2}}=a_{2} \ln \left(\mathrm{C}_{k}\right)+b_{2} \\
\alpha_{\mathrm{H}_{2}-\mathrm{ACH}}=a_{3} \ln \left(\mathrm{C}_{k}\right)+b_{3} \\
\alpha_{\mathrm{ACH}-\mathrm{H}_{2}}=a_{4} \ln \left(\mathrm{C}_{k}\right)+b_{4}
\end{gathered}
$$

where, $\mathrm{C}_{k}$ is the carbon number of the defined compounds. $\alpha_{\mathrm{H}_{2}-\mathrm{CH}_{2}}$ and $\alpha_{\mathrm{CH}_{2}-\mathrm{H}_{2}}$ are the group-interaction parameters between $-\mathrm{CH}_{2}$ and $\mathrm{H}_{2}$ functional groups, $\alpha_{\mathrm{H}_{2}-\mathrm{ACH}}$ and $\alpha_{\mathrm{ACH}-\mathrm{H}_{2}}$ are group-interaction parameters between $\mathrm{ACH}$ and $\mathrm{H}_{2}$ functional groups. Finally, coefficients $a_{n}, b_{n}, c_{n}$, $d_{n}$ are shown in Table 5.

Similar results have been obtained by Florusse et al. (2003); they used a Statistical Associating Fluid Theory (SAFT) model to predict hydrogen solubility in heavy alkanes, where the corresponding cross-binary interaction parameters were obtained as a function of the carbon number as well.

Figures $2 \mathrm{a}$ and $2 \mathrm{~b}$ show experimental $(\diamond)$ and calculated hydrogen solubility data for pyrene and hexatetracontane, respectively. The original group-interaction parameters underestimate hydrogen solubility (----) whereas the predicted values are in better agreement with experimental data (一).

Table 3 summarizes the RAD of all defined components with the original group-interaction parameters and with those given by Equations from (11) to (14).
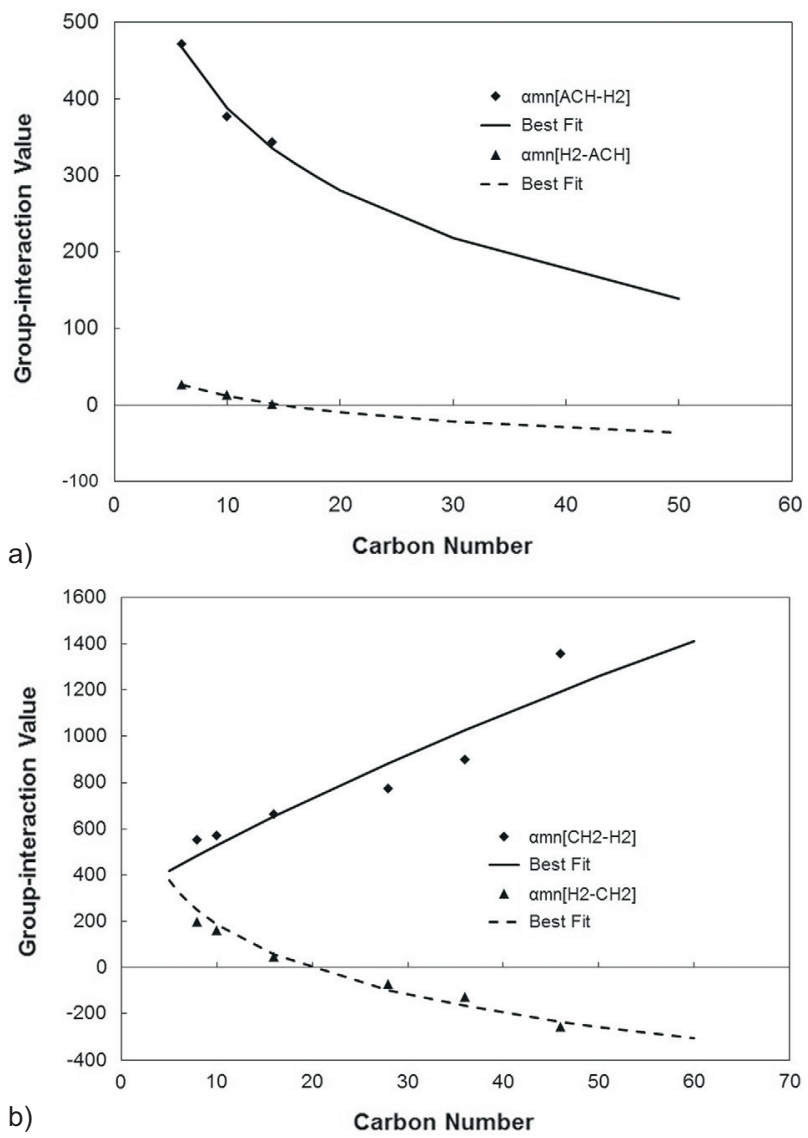

Figure 1

Group-interaction parameters as function of carbon number a) paraffinic compounds, b) aromatic compounds.

\section{SOLUBILITY OF HYDROGEN IN UNDEFINED PETROLEUM FRACTIONS}

As first step, critical properties and molecular pseudostructures of the seven undefined petroleum fractions studied in 
TABLE 5

Group-interaction parameters $\left(\alpha_{n m}\right)$ between functional groups used in this study.

\begin{tabular}{c|c|c|c|c}
\hline Subscript & $a$ & $b$ & $c$ & $d$ \\
\hline 1 & 2369.27 & $4.09 \times 10^{-2}$ & 4.120 & -3051.40 \\
\hline 2 & -275.24 & 820.23 & & \\
\hline 3 & -154.4 & 743.22 & & \\
\hline 4 & -29.74 & 79.98 & & \\
\hline
\end{tabular}

this work were determined using the characterization procedure described in Section 1. Table 6 shows density, molecular weight and hydrogen-carbon ratio of the seven undefined fractions used in this work. As will be discussed later, the last two properties play an important role in modeling such systems with hydrogen. In all cases, the experimental error reported in the literature for hydrogen solubility was $\pm 5 \%$ (Cai et al., 2001; Ji et al., 2013), except for $\mathrm{AB}$ system where such experimental error was not reported (Lal et al., 1999).

Once the molecular pseudostructure is formed with the functional groups from Table 1, it is possible to make a distinction between paraffinic, naphthenic and aromatic contributions through to the no-integer coefficients $\left(v_{j}\right)$ resulting from the minimization process. Notice that although nine functional groups are used in the characterization procedure (see Tab. 1), there are only two main functional groups according to the UNIFAC method: first six functional belong to the main $-\mathrm{CH}_{2}$ functional group, whereas the rest of them belong to the main $\mathrm{ACH}$ functional group. Accordingly, the calculated coefficients $v_{j}$ can be added in order to obtain the carbon number according to these two main functional groups. Therefore, Equations from (11) to (14) can be used to estimate group-interaction parameters between the $\mathrm{H}_{2}$ and the functional groups calculated by the characterization procedure.

As illustration, Figure 3 shows the experimental and predicted hydrogen solubility in CHVGO (at $603.15 \mathrm{~K}$ ) which has a molecular weight of $350 \mathrm{~g} / \mathrm{mol}$. The black diamonds $(\bullet)$ represent the experimental values and the crossed bars represent the experimental reported error of $\pm 5 \%$. Calculations using the original group-interaction parameters (----) underestimates the hydrogen solubility, as it is also observed for the defined hydrocarbons from Table 2; in this case the RAD is $51 \%$. When our proposed correlations, Equations from (11) to (14), are used to estimate group-interaction parameters, the predicted values $(\cdots)$ remains below experimental data, but the RAD is reduced up to $25 \%$. To improve the accuracy of hydrogen solubility
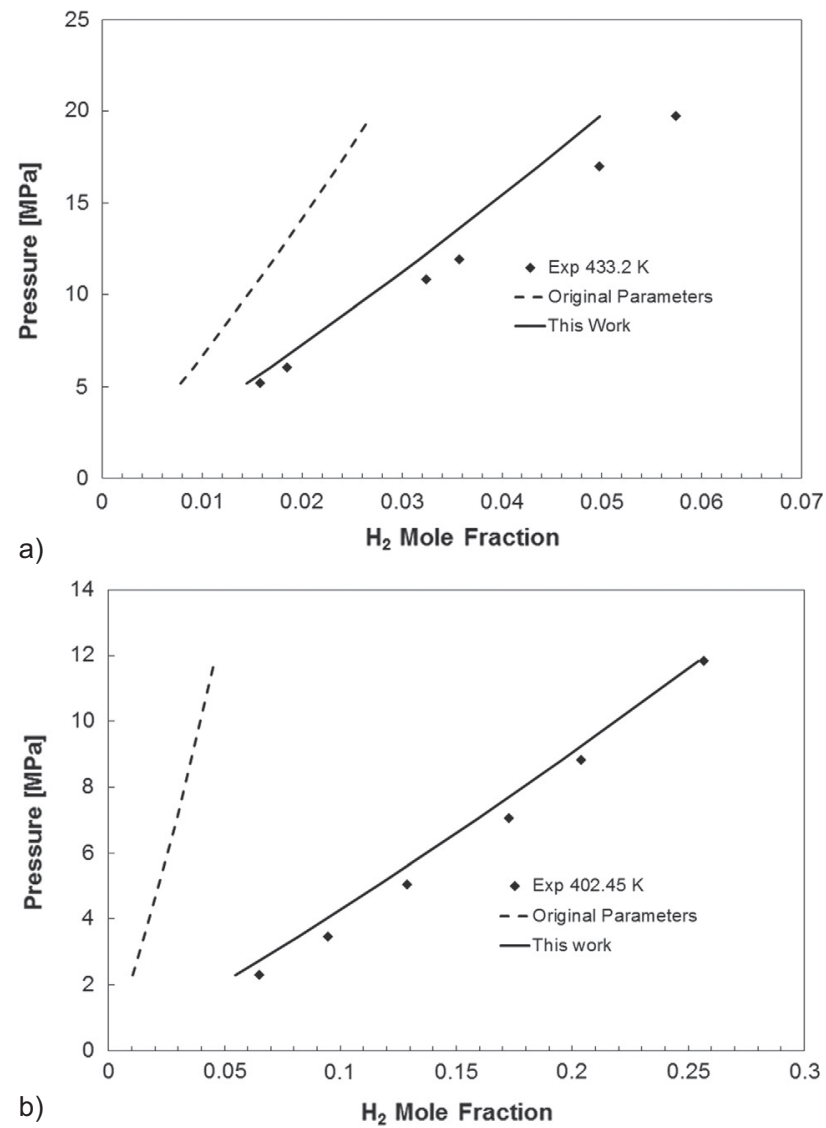

Figure 2

Solubility of hydrogen a) pyrene at $433.2 \mathrm{~K}$, b) hexatetracontane at $402.4 \mathrm{~K}$.

prediction, a modification of the original minimization process of characterization is suggested. This modification consists of including another constraint, in addition to Equations (3) and (4). We believed that this constraint should somehow account for the chemical nature of the undefined fractional. Hence, the Hydrogen-Carbon ratio $(\mathrm{H} / \mathrm{C})$ is proposed as a third constraint. According to experimental observations made by Ji et al. (2013), this parameter may be related to the aromaticity of undefined fraction.

Figure 4 shows the coefficients $\left(v_{j}\right)$ obtained from the original characterization procedure and the modified one with the hydrogen-carbon ratio as constraint. The latter gives smaller values for the aromatic functional groups and larger values for all other functional groups. According to Park et al. (1996) hydrogen solubility decreases as the number of aromatic rings increases. Hence, we believe that the inclusion of the $\mathrm{H} / \mathrm{C}$ ratio may help to construct a 
TABLE 6

Relevant physical properties of the undefined petroleum fractions used in this work.

\begin{tabular}{c|c|c|c|c|c|c|c|c}
\hline Property & Unit & HCGO & KRAR & LHAR & VNAR & CHVGO & CLVGO & AB \\
\hline Density at $293.15 \mathrm{~K}$ & $\mathrm{~kg} / \mathrm{m}^{3}$ & 0.9691 & 0.965 & 0.9821 & 1.0297 & 0.973 & 0.892 & 1.009 \\
\hline Mean molar mass & $\mathrm{g} / \mathrm{mol}$ & 360 & 736.8 & 686.3 & 781.7 & 350 & 250 & 522 \\
\hline H/C ratio & $\mathrm{mol} / \mathrm{mol}$ & 1.51 & 1.6 & 1.57 & 1.42 & 1.52 & 1.74 & 1.51 \\
\hline
\end{tabular}

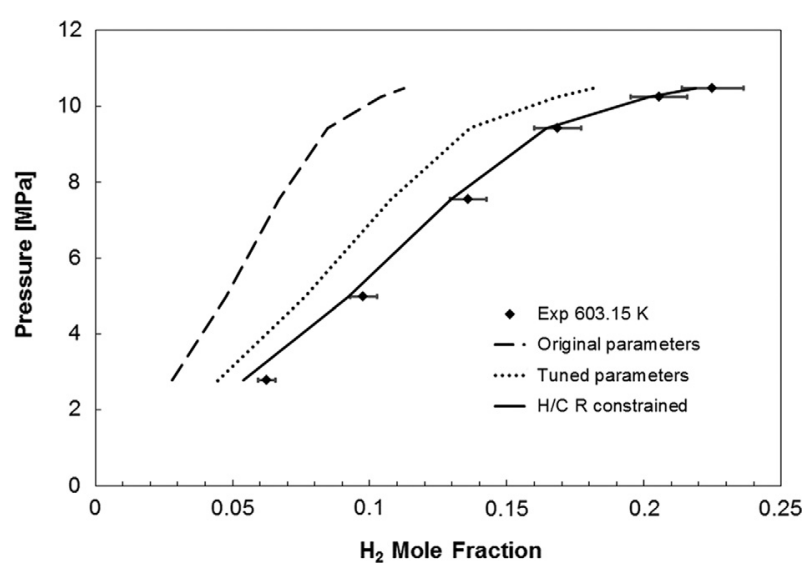

Figure 3

Solubility of hydrogen in CHVGO petroleum fraction at $603.15 \mathrm{~K}$ as a function of group-interaction parameters.

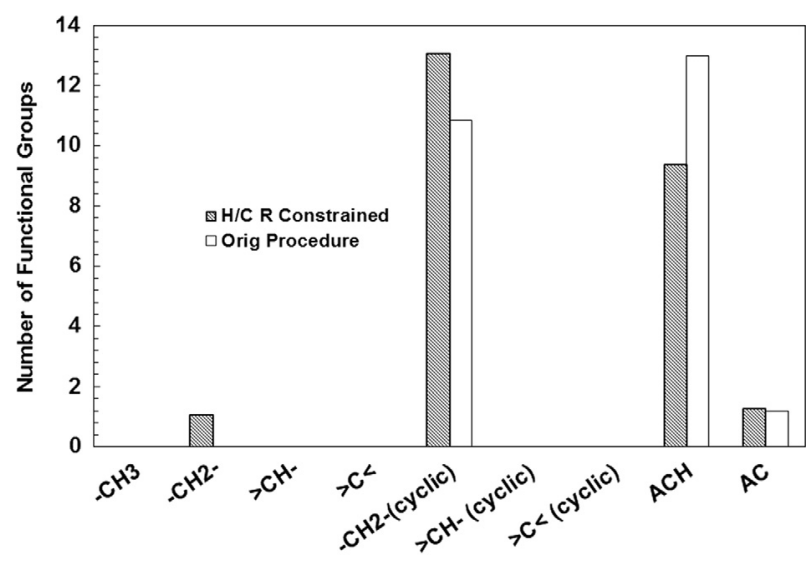

Functional Groups

Figure 4

Coefficients calculated by characterization process.

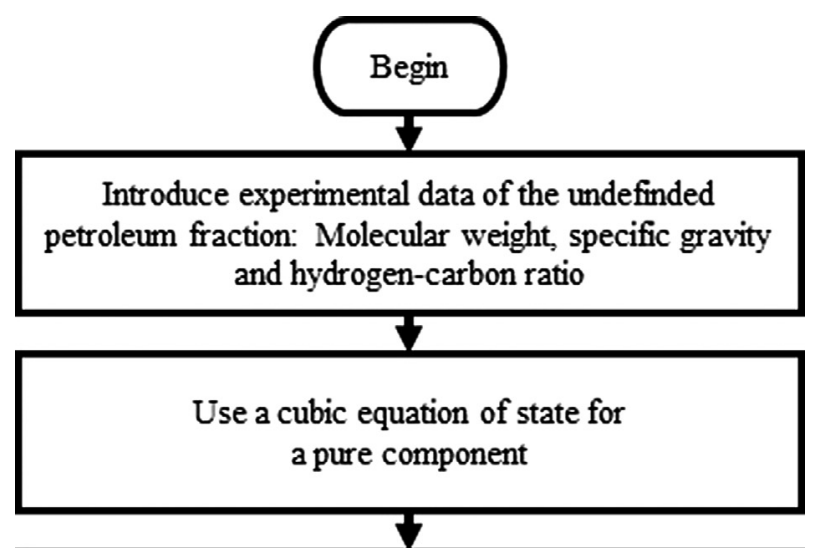

To perform optimization process

Obective Function: $F_{\min }=\phi^{l}$

Constrains:

$$
\begin{gathered}
\text { 1.- }-\sum_{i}^{F G} v_{i} \Delta v_{i}-\frac{M W_{E x p}}{\rho E x p}=0 \\
\text { 2. }-\sum_{i}^{F G} v_{i} M W_{i}-M W_{E x p}=0 \\
\text { 3.- } \sum_{i}^{F G}\left[(H / C)_{i}-(H / C)_{E x p}\right] v_{i}=0
\end{gathered}
$$

Determining critical properties from MG method and group-contribution parameters of $-\mathrm{CH} 2-\mathrm{H} 2$ and $\mathrm{ACH}$ $\mathrm{H} 2$ from pseudoestructure

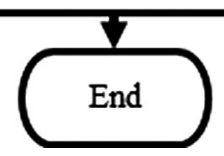

Figure 5

Flow chart of the modified characterization process. pseudostructure in better agreement with its aromatic nature. Figure 3 shows the predicted hydrogen solubility (-) using the modified characterization procedure. As seen, predicted hydrogen solubilities are in better agreement with experimental data $(\mathrm{RAD}=5 \%)$.
The modified characterization procedure is summarized in Figure 5, where the stages are described in a flowchart. Here $(\mathrm{H} / \mathrm{C})_{j}$ is the hydrogen-carbon ratio of a functional group $j$ and $(\mathrm{H} / \mathrm{C})_{\operatorname{Exp}}$ is the experimental hydrogen-carbon ratio of a $i$ undefined petroleum fraction. 


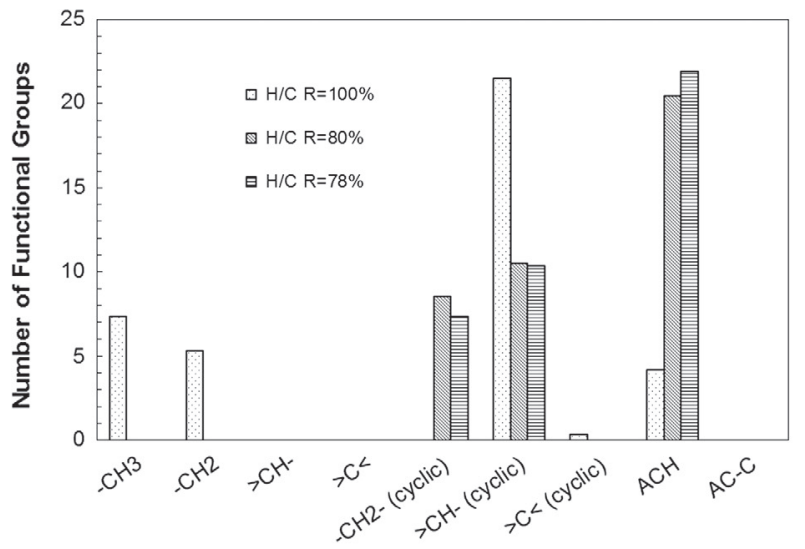

a)
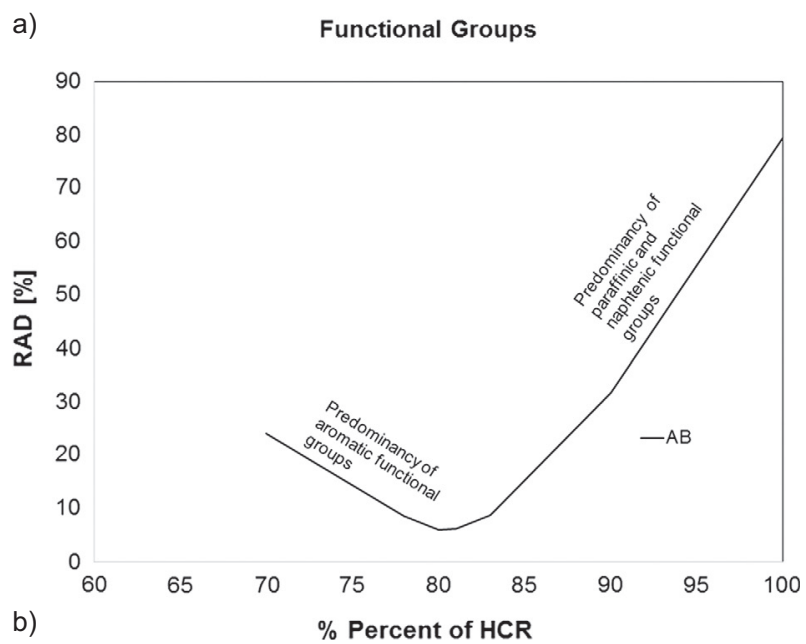

Figure 6

Sensitivity analysis of $\mathrm{H} / \mathrm{C}$ parameter used in the characterization process for $A B$. a) Pseudostructure arrangements of $A B$ depending on percent of the $\mathrm{H} / \mathrm{C}$ ratio, b) RAD $v s$. percent of $\mathrm{H} / \mathrm{C}$ ratio used in the minimization process.

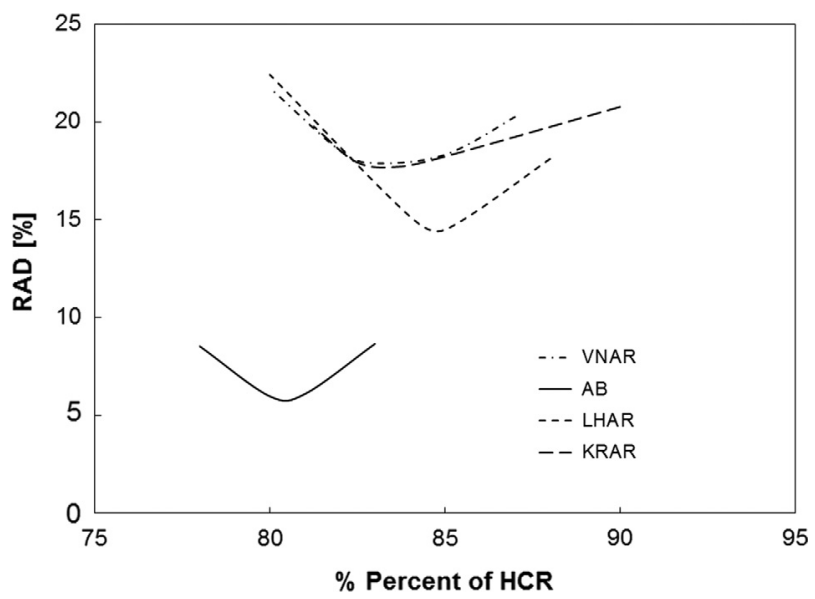

Figure 7

Sensitivity analysis of RAD as a function of $\mathrm{H} / \mathrm{C}$ parameter in the characterization process for different cuts.
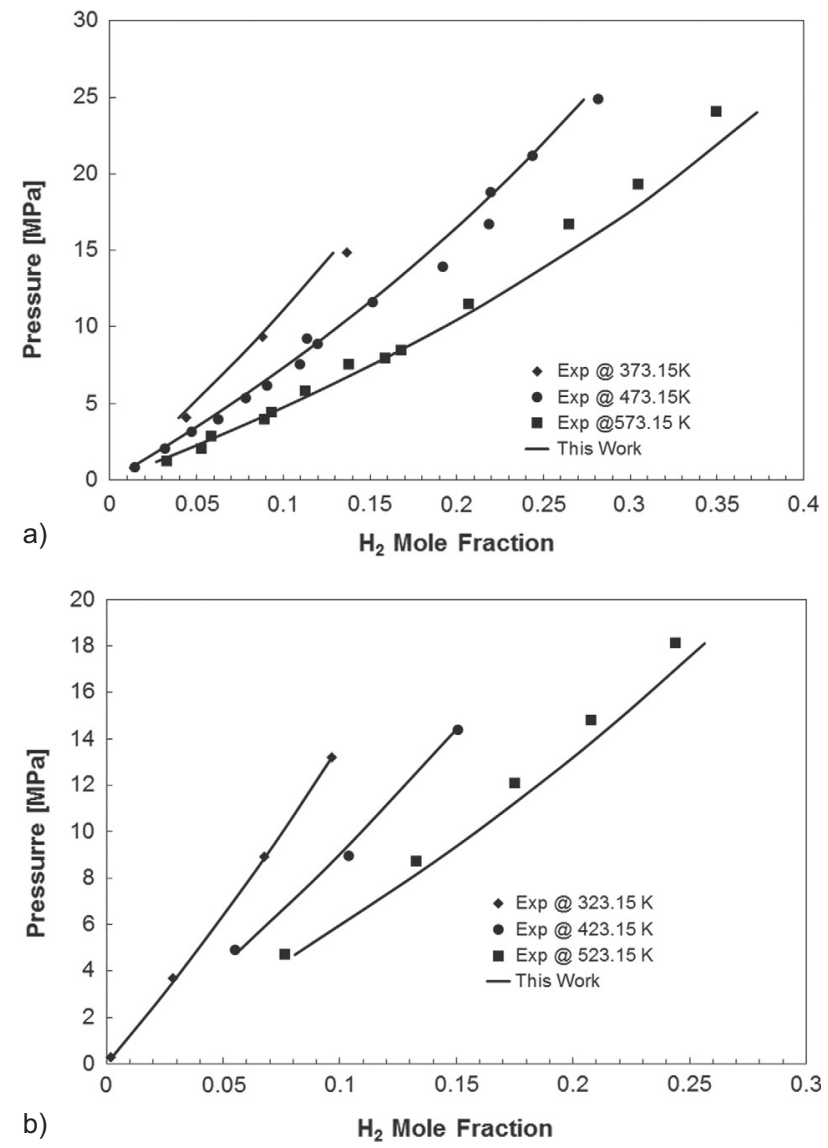

Figure 8

Prediction of hydrogen solubility in Athabasca Bitumen a) at $373.15 \mathrm{~K}, 473.15 \mathrm{~K}$ and $573.15 \mathrm{~K}, \mathrm{~b})$ at $323.15 \mathrm{~K}, 423.5 \mathrm{~K}$ and $523.15 \mathrm{~K}$.

As observed in Table 6, three undefined fractions have molecular weights below $360 \mathrm{~g} / \mathrm{mol}$, whereas the rest of them have values above $500 \mathrm{~g} / \mathrm{mol}$. Although good results were achieved in the former, hydrogen solubility was overestimated in the latter. When the calculated pseudostructures are reviewed, it is found that they are formed mainly by paraffinic and cyclic functional groups and by a small portion of aromatic ones. This seems to be the reason why the hydrogen solubility is overestimated. Hence, a sensitivity analysis was made to know the effect of the $\mathrm{H} / \mathrm{C}$ ratio in the characterization process from Figure 5 .

In Figure $6 \mathrm{a}$, three different pseudostructures of $\mathrm{AB}$ depending on the $\mathrm{H} / \mathrm{C}$ ratio are shown. When $\mathrm{H} / \mathrm{C}$ parameter is set equal to the experimental value, the pseudostructure is mainly formed by paraffinic and naphthenic functional groups and hydrogen solubility is overestimated ( $\mathrm{RAD}>50 \%$ ). In contrast, hydrogen solubility is underestimated $(\mathrm{RAD}>20 \%$ ) when $\mathrm{H} / \mathrm{C}$ parameter is set equal to 
TABLE 7

RAD on prediction of $\mathrm{H}_{2}$ solubility in undefined hydrocarbon fractions.

\begin{tabular}{|c|c|c|c|c|c|c|}
\hline \multirow{2}{*}{$\begin{array}{c}\text { System } \\
\text { HCGO-H }_{2}\end{array}$} & \multicolumn{2}{|c|}{$T_{\text {range }}(\mathrm{K})$} & \multicolumn{2}{|c|}{$P_{\text {range }}(\mathrm{Mpa})$} & \multirow{2}{*}{$\frac{\text { Data points }}{25}$} & \multirow{2}{*}{$\frac{\text { This work RAD }(\%)}{16.1}$} \\
\hline & 423.15 & 623.15 & 1.76 & 9.98 & & \\
\hline KRAR- $\mathrm{H}_{2}$ & 423.15 & 623.15 & 2.03 & 10.7 & 25 & 17.93 \\
\hline LHAR- $\mathrm{H}_{2}$ & 423.15 & 623.15 & 1.23 & 10.83 & 25 & 14.97 \\
\hline VNAR- $\mathrm{H}_{2}$ & 423.15 & 623.15 & 1.64 & 10.74 & 25 & 16.78 \\
\hline CHVGO- $\mathrm{H}_{2}$ & 283.17 & 447.92 & 1.97 & 11.53 & 36 & 13.82 \\
\hline CLVGO-H ${ }_{2}$ & 298.13 & 448.17 & 1.94 & 12.28 & 37 & 12.45 \\
\hline $\mathrm{AB}-\mathrm{H}_{2}$ & 323.15 & 573.15 & 0.26 & 24.85 & 43 & 6.82 \\
\hline
\end{tabular}

$30 \%$ below the experimental value. In latter case, aromatic functional groups predominate over paraffinic and naphthenic ones. Figure $6 \mathrm{~b}$ shows the trend of the RAD as function of the used $\mathrm{H} / \mathrm{C}$ ratio. It can be seen that there is minimum value when $\mathrm{H} / \mathrm{C}$ parameter is set around $80 \%$ of the experimental value; its corresponding pseudostructure is shown in Figure 6a. At this point, it is important to emphasize that the characterization procedure do not intend to make a characterization at molecular level, but look for an average structure that allow to reproduce bulk properties (CarreónCalderón et al., 2012, 2014; Uribe-Vargas et al., 2016).

As with the A/B undefined petroleum fraction, the same sensitivity analysis was made for the VNAR, KRAR, and LAHR fractions. Figure 7 illustrates that minimum values of the RAD are achieved when $H / C$ parameter lies between 80 and $85 \%$ of the experimental value. Therefore, we suggested to set the $\mathrm{H} / \mathrm{C}$ ratio in this interval in order to obtained better results for heavy undefined petroleum fraction with molecular weights above $500 \mathrm{~g} / \mathrm{mol}$.

The results of hydrogen solubility prediction in Athabasca Bitumen $(\mathrm{AB})$ at different temperatures and pressures are illustrated in Figures $8 \mathrm{a}$ and $8 \mathrm{~b}$. Here, the experimental value of the $\mathrm{H} / \mathrm{C}$ ratio is 1.51 , but, according to that previously discussed, it was set equal to 1.208 , obtaining an overall RAD of $6.8 \%$. In Table 7 all results are summarized, the overall RAD being equal to $14.12 \%$.

\section{CONCLUSIONS}

The characterization procedure presented by CarreónCalderón et al. $(2012,2014)$ was extended to predict hydrogen solubility in heavy undefined petroleum fractions including $\mathrm{H}_{2}$ as another functional group, and the hydrogen-carbon ratio as third constraint in the characterization process. Group-interaction parameters between hydrogen and the main functional groups of the UNIFAC approach were calculated through a set of correlations based on experimental vapor-liquid equilibria data of binary mixtures of hydrogen and defined hydrocarbons. These modifications were enough for prediction purposes with molecular weights below $500 \mathrm{~g} / \mathrm{mol}$. For undefined petroleum fraction with molecular weights above $500 \mathrm{~g} / \mathrm{mol}$, the hydrogen-carbon ratio was modified to $80 \%$ of its experimental value. The inclusion of the hydrogen-carbon ratio was revealed as important property in order to construct the hypothetical structures in better accordance with its molecular nature.

\section{ACKNOWLEDGMENTS}

The authors express their gratitude to the Mexican Institute of Petroleum and SENER-CONACyT for financial support through the Y.61006 research project.

\section{REFERENCES}

Cai H.Y., Shaw J.M., Chung K.H. (2001) Hydrogen solubility measurements in heavy oil and bitumen cuts, Fuel 80, 8, 1055-1063.

Carreón-Calderón B., Uribe-Vargas V., Ramírez-Jaramillo E., Ramírez-de-Santiago M. (2012) Thermodynamic characterization of undefined petroleum fractions using group contribution methods, Ind. Eng. Chem. Res. 51, 43, 14188-14198.

Carreón-Calderón B., Uribe-Vargas V., Ramírez-de-Santiago M., Ramírez-Jaramillo E. (2014) Thermodynamic characterization of heavy petroleum fluids using group contribution methods, Ind. Eng. Chem. Res. 53, 13, 5598-5607.

Chávez L.M., Alonso F., Ancheyta J. (2014) Vapor-liquid equilibrium of hydrogen-hydrocarbon systems and its effects on hydroprocessing reactors, Fuel 138, 156-175.

Chen J., Mulgundmath V., Wang N. (2011) Accounting for vaporliquid equilibrium in the modeling and simulation of a commercial hydrotreating reactor, Ind. Eng. Chem. Res. 50, 1571-1579. 
Connolly J.F., Kandalic G.A. (1986) Gas solubilities, vapor-liquid equilibria, and partial molal volumes in some hydrogenhydrocarbon systems, J. Chem. Eng. Data 31, 4, 396-406.

Deiters U.K. (2013) Comments on the modeling of hydrogen and hydrogen-containing mixtures with cubic equations of state, Fluid Phase Equilib. 352, 93-96.

Elbro H.S., Fredenslund A., Rasmussen P. (1991) Group contribution method for the prediction of liquid densities as a function of temperature for solvents, oligomers, and polymers, Ind. Eng. Chem. Res. 30, 12, 2576-2582.

Firoozabadi A. (1988) Reservoir-Fluid Phase Behavior and Volumetric Prediction With Equations of State (includes associated papers 18400 and 18579), J. Petrol. Technol. 40, 397-406.

Florusse L.J., Peters C.J., Pàmies J.C., Vega L.F., Meijer H. (2003) Solubility of hydrogen in heavy $n$-alkanes: experiments and SAFT modeling, AIChE J. 49, 12, 3260-3269.

Hook B.D. (1985) Effect of feed volatility on conversion in trickle bed reactors, Ind. Eng. Chem. Fundam. 24, 3, 398-401, Available at: http://www.scopus.com/inward/record.url?eid=2-s2.0-0022110777\& partnerID=40\&md5=a9e63ff4de18848d030986e035bd2866.

Horstmann S., Jabłoniec A., Krafczyk J., Fischer K., Gmehling J. (2005) PSRK group contribution equation of state: comprehensive revision and extension IV, including critical constants and $\alpha$-function parameters for 1000 components, Fluid Phase Equilib. 227, 2, 157-164.

Ihmels E.C., Gmehling J. (2003) Extension and revision of the group contribution method GCVOL for the prediction of pure compound liquid densities, Ind. Eng. Chem. Res. 42, 2, 408-412.

Jaubert J.N., Privat R., Mutelet F. (2010) Predicting the phase equilibria of synthetic petroleum fluids with the PPR78 approach, AIChE J. 56, 12, 3225-3235.

Ji S., Wang Z., Guo A., Zhou Y., Chen K. (2013) Determination of hydrogen solubility in heavy fractions of crude oils by a modified direct method, J. Chem. Eng. Data 58, 12, 3453-3457.

Joback K.G., Reid R.C. (1987) Estimation of pure-component properties from group-contributions, Chem. Eng. Commun. 57, 1-6, 233-243.

Lal D., Otto F.D., Mather A.E. (1999) Solubility of hydrogen in Athabasca bitumen, Fuel 78, 12, 1437-1441.

Lee B.I., Kesler M.G. (1975) A Generalized Thermodynamic Correlation Based on Three-Parameter Corresponding, AIChE J. 21, 3, 510-527.

Lin H.M., Kim H., Guo T., Chao K.C. (1985) Equilibrium vaporization of a coal liquid from a Kentucky No. 9 coal, Ind. Eng. Chem. Process Des. Dev. 24, 1049-1055.
Marrero J., Gani R. (2001) Group-contribution based estimation of pure component properties, Fluid Phase Equilib. 183-184, 183-208.

Michelsen M.L. (1990) A modified Huron-Vidal mixing rule for cubic equations of state, Fluid Phase Equilib. 60, 1-2, 213-219.

Nichols W.B., Reamer H.H., Sage B.H. (1957) Volumetric and phase behavior in the hydrogen-n-hexane system, AIChE J. 3, 2, 262-267.

Park J., Robinson R.L., Gasem K.A.M. (1996) Solubilities of Hydrogen in Aromatic Hydrocarbons from 323 to $433 \mathrm{~K}$ and Pressures to 21.7 MPa, J. Chem. Eng. Data 41, 1, 70-73.

Pedersen K.S., Milter J., Sørensen H. (2004) Cubic equations of state applied to HT/HP and highly aromatic fluids, SPE J. 9, 186-192.

Pellegrini L.A., Gamba S., Calemma V., Bonomi S. (2008) Modelling of hydrocracking with vapour - liquid equilibrium, Chem. Eng. Sci. 63, 4285-4291.

Peng D.-Y., Robinson D.B. (1976) A new two-constant equation of state, Ind. Eng. Chem. Fundam. 15, 1, 59-64.

Privat R., Jaubert J.N. (2013) Classification of global fluid-phase equilibrium behaviors in binary systems, Chem. Eng. Res. Des. 91, 10, 1807-1839.

Qian J.W., Jaubert J.N., Privat R. (2013) Phase equilibria in hydrogen-containing binary systems modeled with the Peng-Robinson equation of state and temperature-dependent binary interaction parameters calculated through a group-contribution method, J. Supercrit. Fluids 75, 58-71.

Saajanlehto M., Uusi-Kyyny P., Alopaeus V. (2014) Hydrogen solubility in heavy oil systems: experiments and modeling, Fuel 137, 393-404.

Uribe-Vargas V., Carreón-Calderón B., Ramírez-Jaramillo E., Ramírez-de-Santiago M. (2016) Thermodynamic characterization of undefined petroleum fractions of gas condensate using group contribution, Oil Gas Sci. Technol. - Rev. IFP 71, 1, 5.

$\mathrm{Xu}$ X., Jaubert J.-N., Privat R., Duchet-Suchaux P., Braña-Mulero F. (2015) Predicting binary-interaction parameters of cubic equations of state for petroleum fluids containing pseudo-components, Ind. Eng. Chem. Res. 54, 10, 2816-2824.

Young C.L. (1981) Hydrogen and Deuterium (Solubility Data Series), Pergamon Press, Australia, pp. 314-321.

Manuscript submitted in June 2016

Manuscript accepted in November 2016

Published online in January 2017

Cite this article as: H. Aguilar-Cisneros, V. Uribe-Vargas, B. Carreón-Calderón, J.M. Domínguez-Esquivel and M. Ramirez-deSantiago (2017). Hydrogen Solubility in Heavy Undefined Petroleum Fractions Using Group Contributions Methods, Oil Gas Sci. Technol 72, 2. 